University of Montana

ScholarWorks at University of Montana

$1-2015$

\title{
Faculty Research and Publication Practices
}

Kate Zoellner

University of Montana - Missoula, kate.zoellner@umontana.edu

Samantha Hines

University of Montana - Missoula, samhines@gmail.com

Teressa M. Keenan

University of Montana - Missoula, teressa.keenan@umontana.edu

Sue Samson

University of Montana - Missoula, sue.samson@umontana.edu

Follow this and additional works at: https://scholarworks.umt.edu/ml_pubs

Part of the Library and Information Science Commons

Let us know how access to this document benefits you.

\section{Recommended Citation}

Zoellner, Kate; Hines, Samantha; Keenan, Teressa M.; and Samson, Sue, "Faculty Research and Publication Practices" (2015). Mansfield Library Faculty Publications. 22.

https://scholarworks.umt.edu/ml_pubs/22

This Article is brought to you for free and open access by the Mansfield Library at ScholarWorks at University of Montana. It has been accepted for inclusion in Mansfield Library Faculty Publications by an authorized administrator of ScholarWorks at University of Montana. For more information, please contact scholarworks@mso.umt.edu. 


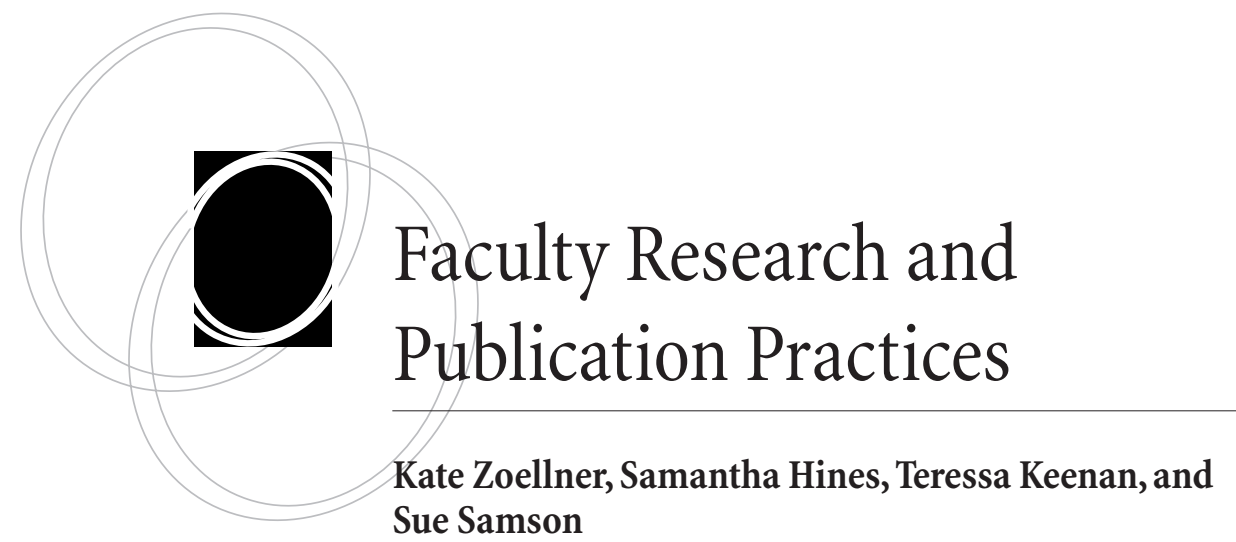

abstract: Understanding faculty work practices can translate into improved library services. This study documents how education and behavioral science faculty locate, retrieve, and use information resources for research and writing and how they publish and store their research materials. The authors interviewed twelve professors using a structured interview instrument and analyzed the data. Findings cover the role of library services in scholarly research processes, as well as the use of software and technologies and the challenges faculty face.

\section{Introduction}

$\mathrm{U}$ nderstanding the research and publishing practices of faculty is critical to the ability of librarians to support a university's scholarship and teaching. This study builds on the methodology of ethnographic research in libraries as well as broader research on perceptions of libraries in various academic disciplines, information-seeking behaviors, scholarly communication, and open access. The investigators undertook this project to address three primary goals: to understand the research and publication practices of faculty; to recommend new or modified library services based on these findings; and to inform and recommend marketing and development initiatives to support an institutional repository. Specifically, the authors designed this study to document how select professors in education and the behavioral sciences locate, retrieve, and use information resources for research and writing and how they publish and store their research materials.

\section{Literature Review}

Librarians' interest in how professors find, retrieve, and utilize information sources for research and writing is not new. As a commonly held part of the academic library vision, providing information resources for teachers and scholars in support of their courses portal: Libraries and the Academy, Vol. 15, No. 1 (2015), pp. 111-131.

Copyright $\odot 2015$ by Johns Hopkins University Press, Baltimore, MD 21218. 
and publications is part of our institutional mission. However, as technology advances, the use of information by faculty evolves into new patterns for us to examine. Therefore,

...providing information resources for teachers and scholars in support of their courses and publications is part of our institutional mission. current literature on the subject takes advantage of research into new modes of information searching, dissemination, and use.

Most recent librarianship-based studies of faculty research practices focus on instructors in specific academic disciplines. Karen Rupp-Serrano and Sarah Robbins examined information needs of education professors from twenty different institutions and found that access to scholarly journal articles topped the list of needs that teachers expressed regarding their research, followed by Internet resources and conversation with colleagues. ${ }^{1}$ Faculty in their study sought information at least weekly in their teaching and research endeavors and generally felt satisfied with the library's offerings in support of their work. ${ }^{2}$ Inna Shpilko, examining professors in the health sciences, found similar results with instructors in that field, who ranked journal articles and conference proceedings highest in importance. ${ }^{3}$ Sarah Robbins, Debra Engel, and Christina Kulp looked at engineering faculty from twenty research institutions and found that, across institutions, most university teachers write for research, prepare for instruction, and keep current in their field at least monthly. They rely predominantly upon information received from journal articles and conference attendance to do so. ${ }^{4}$ These respondents chiefly used library resources available electronically, along with interlibrary loans. ${ }^{5}$

Robbins and Rupp-Serrano found that general information-seeking behaviors held true across disciplines in a comparison study of Robbins, Engel, and Kulp's 2011 research and their own 2013 study. ${ }^{6}$ However, they suggest that information related to specific library practices, services, or facilities ought to

...the traditional publishing model still rules, and ... conferences play a key role in communicating research. be validated locally. ${ }^{7}$ The often-cited 2012 Ithaka Study took a multidisciplinary approach to capturing research and teaching practices and found a growing reliance on digitally available materials across the board. The study also reported general faculty satisfaction with what is available to them online and via their libraries. ${ }^{8}$ The 2012 Ithaka Study is also a treasure trove of information on scholarly communications. The study's authors note that the traditional publishing model still rules, and that conferences play a key role in communicating research. ${ }^{9}$

Ethnographic research has become widespread when examining questions of information use in a library or university setting, with a flurry of publications after about $2005 .{ }^{10}$ This approach is the focus of several institutes offered by organizations such as the Council on Library and Information Resources (CLIR) and has attracted grant and institutional support from many institutions, resulting in such studies as the ERIAL (Ethnographic Research in Illinois Academic Libraries) Project. 
In their thorough examination of ethnography in library and information sciences literature, Michael Khoo, Lily Rozaklis, and Catherine Hall define ethnography as "a complex, in-situ research approach that provides understanding of research subjects in naturally occurring settings." They continue: "Ethnographic approaches draw on a toolkit of ethnographic and design approaches, such as observation, interviews, focus groups, cultural probes, and others, which can be combined and triangulated to gain insights into users' behaviors."11 Ellen Freeman and Marilyn Pukkila point out the benefits of ethnographic work in building relationships with faculty and finding authentic evidence of library users' research practices. ${ }^{12}$ Valeda Dent Goodman further identifies the value of ethnographic research in a distributed information environment, where users can seek out information in a variety of locations and using multiple modalities. ${ }^{13}$ Ethnographic methods were the clear choice for the researchers to understand the information-seeking and publishing behaviors of faculty.

\section{Methods}

This project used a within-subjects design, asking the same questions of all participants at a single site. The investigators chose participants with purposeful sampling techniques-that is, methods based on the purpose of the study. The authors recruited participants from the University of Montana and limited them to tenure-track faculty from the College of Education and Human Sciences and the Psychology Department.

Once the university's Institutional Review Board had exempted the study from review, the investigators contacted participants via e-mail, telephone, or both to arrange face-to-face interviews. Twelve individuals participated in the study. Three of the participants were female and nine were male. Their experience level was divided equally, four each at the levels of assistant professor, associate professor, and full professor. Those interviewed represented the following departments within the College of Education: Communicative Sciences and Disorders (two individuals), Curriculum and Instruction (three individuals), Educational Leadership (one individual), and Health and Human Performance (two individuals); and four individuals from the Psychology Department.

All interviews lasted approximately forty-five minutes. The authors interviewed participants in their campus offices. In addition to being a comfortable environment for the participant, the location provided easy access to faculty members' research materials and examples of how they went about their work. Each interview began with an explanation of the purpose of the research. The investigators assured participants that their participation was optional and the interview would remain confidential.

The first part of the interview focused on general information regarding the individual's research. The interviewers requested that participants describe a current research project on which they were working and share a resource they were reading that was related to that project. They were then asked how they discovered and acquired the item and what challenges they faced during that process. The second portion of the interview focused more specifically on the library and its role in their research. The third segment of the interview addressed the participant's organization and publication efforts related to the research. The authors of the study inquired how the professors store and organize their research resources and notes, what works well for them, and what 
challenges they face during that stage of the research process. The interviewers also requested participants to share where they recently published or presented their research and why they chose that outlet. Time permitting, the participants were each asked to describe their perfect research scenario; if they could have anything they wanted, what would make it easier for them to do their work? Each interview ended with a tour of the participant's office or lab. The interview instrument, appended, was based on questions from both the University of Minnesota Libraries' Andrew W. Mellon Foundation academic support study as well as the Faculty Interview Protocol from the CLIR faculty research behavior workshop..$^{14}$

All interviews were recorded using a digital flip video camera and a digital audio recorder; the interviewers took no field notes. The audio recording was used to transcribe the interview at a later time. The video recording was used to document the environment in which the participants conducted their research and served as a backup in case of technical difficulties with the audio equipment. Two researchers attended each interview; one conducted the conversation, while the other recorded the session. The authors used NVivo qualitative data analysis software for the purpose of data management, organization, and analysis. The interviews were transcribed verbatim into Microsoft Word documents formatted for consistency and compatibility with NVivo. The investigators did an initial analysis of the transcripts to identify the main ideas or themes of the interviews. The next step in the analysis process involved coding or chunking the data into nodes, which were then arranged into tree node hierarchies. Finally, the researchers analyzed the data and the interview questions to gain additional insight regarding commonalities and uniqueness among the interviews.

\section{Study Limitations}

The main study limitations were the number of subjects interviewed, the disciplines covered, and the generalizability of results. The intent was to understand the research and publishing practices of faculty in the education and behavioral sciences, yet there are disagreements related to the exact disciplines that fall within those categories; for example, the research conducted by scholars in communicative sciences or human performance often varies greatly from that done by education professors. A future iteration of the study might focus on a specific department, or include a larger sample of instructors from each department. Readers should keep in mind the nature of qualitative research is to provide an in-depth exploration of a topic, and thus the results of this study were not meant to be, and are not, generalizable.

\section{Analysis and Results}

\section{Research Processes and Practices}

The investigators invited the faculty to describe a current research project and the process they used to locate and retrieve something they were reading for that research, as well as to identify any challenges they faced in the process. While the questions were specific to a project and item, the responses broadened to include comments on the participants' information-seeking practices generally and their previous research experiences. Subse- 
quently in the interview, the investigators questioned faculty about the role of the library in their research, which led some professors to further discuss their research practices.

Faculty acquired their on-hand or in-mind item through either active searching or professional affiliations and practices. Most professors reported that they searched licensed electronic databases, physical library collections, and the Web sites of professional associations and booksellers. Others said that they acquired the source from a textbook vendor or colleague, or came across the item while reading a print journal obtained through a personal subscription or preparing instructional materials. The ways in which the faculty came to a particular information source as the result of active searching were seemingly guided by their research questions and methodologies. For example, two professors whose research involved conducting systematic reviews explained searching select subject-specific databases using controlled vocabularies, while the resources consulted by two other faculty members working on historical research projects included archives, special library collections, and eBay:

I look through ERIC, PsycINFO, a little bit in the medical database-related to some topics ... we [use] different key search terms that we've developed based on using the thesauruses from the different databases, and systematically go through all those, and pool all those citations into, I've used mainly Reference Manager, but I think this time I'll use EndNote, or one of the ones the library supports. And, then I weed out the duplicates in that first database and screen the abstracts to see which ones seem like a match for our inclusionary criteria and then actually retrieve the hard copies of those journal articles; screen those, delete the ones that don't, once I read the full text etc., and then archive those and use them for the study. In addition, we pick out sort of the most prolific and the most famous experts around a particular topical area, nationally or internationally, and do a hand search by author name, to see if we've missed anything by a particular author. And, then I also search forward from bibliographic sources for other meta-analyses or systematic reviews, or publications that seem particularly striking, to the materials that we're reviewing.

Assistant Professor C.

While not clearly asked to, a few respondents outlined an overall strategy for their research beginning with a statement such as "I have a sequence of events that will occur" (Full Professor K.), followed by listing the discrete steps they take to locate information. For example, the types of materials they sequentially search (books, then newspaper articles), the types of sources (secondary, then primary), or the means by which they seek information (online, then physically in a library):

I generally do a few different things. One, I do an online search for articles concerning the said person or event or book or what-have-you. I walk the stacks to find supporting literature... So, I'll do the online search, I'll walk the stacks. Typically what I've done- - these books I bought off of eBay,
Faculty expressed the need to be comprehensive in their find- ings of relevant sources, which sometimes involved reviewing hundreds of search results as well as tracking down references from bibliographies or studies cited in systematic reviews.


actually—so, I'll try and find primary source material on eBay ... and then I generally go to [another university's] Libraries ... and see what kinds of materials they have there if I can't get access online.

Assistant Professor D.

Faculty expressed the need to be comprehensive in their findings of relevant sources, which sometimes involved reviewing hundreds of search results as well as tracking down references from bibliographies or studies cited in systematic reviews:

If I have hundreds of different results then I'll go through them one by one ... I'll look through the abstracts. This slash means we one, already have it, or that a previous search with slightly different search terms already had this result so we don't have to look at it. But pretty much at this point I go through when I look at the abstracts and based on the abstracts I'll put a "no" or I'll put a " $Y$ " next to it, and if it's a " $Y$ " it means I want to look at it more closely.

Associate Professor G.

Faculty used keywords, subject terms, and Boolean logic in searching specific databases to establish search results, which they then pool, eliminate duplications from,

\section{The participants typically saved electronic versions of items on their computers, yet often printed out the documents when they needed to work with them, such as to take notes.} screen, weed, and acquire. They acquired articles via the library's online resources, through the use of interlibrary loan, or as a direct purchase. The participants typically saved electronic versions of items on their computers, yet often printed out the documents when they needed to work with them, such as to take notes. Professors have become more frequent users of journal articles over books because of this online availability. At least one faculty member consciously passes over physical books as an information source:

I'm much more likely to use journal articles because they are so readily available. In fact, that's changed my reading and I feel badly about it because I'm less likely to go for a book where I've got to wait for it or physically go over to get it.

Full Professor L.

The main exception was that the professors conducting historical research placed more emphasis on physical books. Such researchers acquired books through browsing library shelves, consulting archives and special collections, or searching bookseller Web sites. Citations and abstracts were not discussed in this context, likely because the items were found outside of electronic systems that would provide the citation data for them to collect.

Overall, the professors articulated multistep actions when discussing their use of licensed electronic resources via the library. Their descriptions of locating sources through professional association Web sites or journals were less structured, likely due to the 
complexity of finding information in those resources. Their comments regarding acquiring sources via professional association Web sites, connections, and research partners were also less concrete, likely given they were not searching for those resources-their professional affiliations led others to share sources with them, and they consulted their professional associations to gauge the status of research in their field. But these sources were equally valuable:

The [association] Web page is pretty good at linking up a lot of the research ... I probably look at it every semester. I'll take a peek at it, look at it, tease it out; I have students look at it, and then I look at the major overarching research areas and have them explore what each one of those are to get a feel for what it's all about.

Associate Professor E.

There's a lot of exchange of articles between different colleagues; if you see something interesting, send it to [Roy], if you see something interesting you pass it on, that kind of personal exchange.

Full Professor J.

While faculty searched when developing instructional materials, they did not do so in the focused way they searched when conducting their own literature review. Associate Professor E. indicated that he would use Google if he wanted "to do a quick search for some [articles] for a class that might be an easy way to do it, get a couple hits, great, this looks engaging, and gets them interested, that kind of thing." He went on to explain: "But if I really want to get into being able to support background research behind those questionnaires, I'm going to need a library search engine that's more sophisticated."

In the faculty's role as research advisers, the connections between teaching and research in terms of the research process seem to blend. And scholars acquired items via their students when the students served as their research assistants, in a sense their research partners, too:

We have a journal club in my research lab where any of the projects that we have going on we pull relevant articles and work with those. We read them as a research group.

Associate Professor H.

We are fortunate enough to have doctoral graduate assistants and that is who is doing a lot of our initial research. I really feel that they are probably more proficient in the library than I am, because I'll just walk down to them and say, "Here's what I need," and they'll start bringing stuff in to me and checking and we start kind of refining our search that way.

Associate Professor F.

\section{Research Challenges}

The professors generally seemed comfortable with their search practices and their ability to locate relevant information. Assistant Professor C. commented, "I've gotten better over the years at finessing the search terms and mak-
The professors generally seemed comfortable with their search practices and their ability to locate relevant information. 
ing sure, you know, I go big enough or more specific enough depending on what kind of hits I'm getting." Asked if they faced any challenges in the process of finding and accessing items, faculty acknowledged that ensuring they searched comprehensively and making use of the results list produced by their search were concerns and difficulties:

With the card catalog you knew when you were at the end, right? That's always, electronically, what database haven't I checked here?

Associate Professor F.

It's not clear to me that we use particularly good [search] strategies. The way I approach it may be different than folks down the hall approach it. I think that probably makes a difference in the end, but it's not real clear how to quantify that. I suppose you could.

Full Professor J.

Associate Professor G. indicated that knowing the exact content of each electronic database would impact his search practices, that his current practice is potentially inefficient:

I want to know which journals PsycINFO accesses and I'm sure there's a way to find out and I want to know which ones Academic Search Premier accesses and just to know where the overlap is ... If there are unique journals that are only covered by one or the other then that would be a rationale for searching both.

In addition to the challenge of searching comprehensively, faculty experienced difficulty determining how to access items, either electronically or in print. According to the participants interviewed, the results lists within licensed databases are confusing as is the "article linker" page on the library Web site. Both assistant-level faculty and full professors found this step in the process confusing: "We're just uncertain sometimes if it's actually at the library and if we just need to go get a hard copy and make a photocopy of it, or if there is a link to a full text online," said Assistant Professor A.

The other challenge mentioned was time. Researchers emphasized the need to find time not only to develop research projects and to search but also to do their writing without interruption:

I wish I had more time for it. Being a faculty member is [a] fun and exciting experience; I really love what I do. I also feel like I have a lot of time that goes into teaching, which is good, I'm a teacher. I have a lot of time that goes into committee work and other service. By the time that all of that is done, research often gets the short shrift for me.

Associate Professor H.

I go hide elsewhere. I go to coffee shops; I like to write in coffee shops.

Assistant Professor B.

Finding financial support for research was another challenge that faculty faced. While there are sources of funding that scholars can use to help offset costs, the opportunities are competitive, not always easy to find, or not available in the needed amount:

It would be nice to have extra money to do pilot studies and things like that. When your options are, you are either doing a pro bono study, as I call them, you are doing something 
as a pilot study and you have absolutely no funding for it whatsoever, or you need to write a grant to NIH to get tens of thousands, or ideally hundreds of thousands dollars, it really doesn't leave much room for the in-between stuff, the studies that require a little bit of money but not a lot. I've had a university grant before that was helpful with that. I've had other small grants that are beneficial with those types of studies. There are a lot of ideas that I have where I think this is not a $\$ 600,000$ idea, this is a $\$ 10,000$ idea, but no one gives you $\$ 10,000$.

Associate Professor H.

\section{The Library's Role}

When the interviewers asked researchers about the role of the library in their research, the scholars discussed three things: collections, the Web site, and personnel. Typical of the responses was that of Assistant Professor A., who said that the library plays "a huge role. A primary role. I get everything, I mean I love that I can do everything online now, just about, that's where I get everything." Faculty indicated that they use the library's collections throughout a research project: they searched library databases to conduct literature reviews, to acquire specific journal articles online or via interlibrary loan, and to continually update their searches.

Study participants commended improvements in the library's electronic holdings during the past five to ten years:

The sheer amount of information is phenomenal, it's definitely mind-boggling. It's like the Library of Alexandria is on your computer. In regards to research, it's sort of like the sky is the limit in that regard.

Assistant Professor D.

When I first came here in 2003 some of the key journals were not available through our library, either we didn't have them in print or we didn't have online access. That's changed dramatically. Whenever, through our library representative, we've asked for any availability of things, those journals have become available. And, of course, with increased online access to a lot of the different portals for those it's been really helpful.

Associate Professor H.

Faculty reported that they consult the library Web site and discussed their experiences when they came to the site with a clear goal in mind but could not achieve that goal or find the service they needed:

I use the Mansfield Library, I look at it daily probably, a couple of times a week at least.

Full Professor J.

OK, here's where I don't understand or there's a problem in terms of the library, and that is "check for a paper copy." Why do I have to?

Full Professor L.

I think if I didn't know this place from Adam I would have a hell of a time finding things. That actually could be said about almost any aspect of our Web site, which is cluttered, nonlinear, and makes no sense to anyone.

Associate Professor G. 
The specific liaison librarian who represents the professors interviewed for the project garnered expressions of gratitude. Professors appreciated the support their

Professors appreciated the support their liaison librarian provided them both through instruction in their classes and by acquiring resources for the collection in support of their teaching and research. liaison librarian provided them both through instruction in their classes and by acquiring resources for the collection in support of their teaching and research:

[Our liaison librarian] has been such a phenomenal resource... Because she's done presentations in my grad research classes. Also several times I've requested materials, because I've only been here three years and I came in with an idea of some things that worked for me in other places that we didn't have here.

Assistant Professor C.

Generalized statements commended librarians on knowing "where to find supplementary materials" (Assistant Professor D.) and "how to do that process of searching" (Full Professor J.). In addition, the participants singled out particular areas in the library as supportive of faculty research: Full Professor K. stated, "Staff members at the Archives are wonderful." Other services mentioned included course reserves, interlibrary loan, and printing.

Additionally, faculty indicated a need for graduate students to become well versed in using library resources both for their own research and for providing effective and efficient assistance to their instructors' research projects. Some researchers asked the liaison librarian to provide instruction within their graduate classes; others recommended graduate student library orientations.

\section{Software and Technologies}

The interviewers asked faculty to describe the role of technology in their research, which led them to discuss the ways in which desktop software, cloud-based tools, and physical equipment support their work. The professors mentioned a wide range of software and Web-based tools that assist the different stages of their research. Microsoft Word is their preferred writing software, and they mentioned Google Documents as a tool used for group writing. Additional programs utilized by those interviewed include Word and NVivo for qualitative analysis; Comprehensive Meta-Analysis for measuring effectsizes - that is, to assess the strength of a relationship between two variables; Bookends, EndNote, Reference Manager, and RefWorks for bibliographic management; geographic information system (GIS) software for mapping; graphic software for creating charts and graphs; and Keynote and PowerPoint for presentations. The professors cited both Excel and SPSS (Statistical Package for the Social Sciences) for statistical analysis and often discussed them in tandem. Associate Professor H. said, "Certainly for data analysis I use SPSS primarily. I do a good bit of analyses that I can in Excel, because it's fairly simple stuff, straightforward statistics." 
The faculty members based their choice of software foremost on the task they aimed to accomplish. Other factors included cost, use experience, system operability, and product support. In discussing his choice of a bibliographic management software, Associate Professor G. stated that one product he used "seemed to crash, I lost data and I just got tired with it" and that it had an "exorbitant" cost. As a result, he researched other options and found one that "syncs up with my Word, so I can cite while I write" and for which he felt "the price was right." He also mentioned that the individual who runs the company is prompt in responding to questions. Assistant Professor C. also noted the role of support in software use: "This time I'll use EndNote, or one of the ones the library supports."

The other influence in software selection is new products or technologies and disciplinary practices. When Assistant Professor A. purchased an iPad, the Keynote software was included; thus she began to use it. Keeping current in their disciplines and wanting to provide guidance to graduate students also led to the use of new software:

I still prefer longhand. But, I'm not proficient in NVivo. Reading in the field and knowing that the reviews were saying that the problems with NUD*IST [Non-numerical Unstructured Data Indexing Searching and Theorizing] have been resolved. Then reading in the qualitative field and seeing more of the analysis reported as using NVivo. Then feeling a responsibility to expose doctoral students to that; even though I need to get my hands on it, I don't think they do.

Associate Professor F.

Faculty discussed physical technologies in terms of how they facilitated productivity, eased work, captured research data, or provided storage. The study participants used computers for all stages of the research, writing, and publication process. Some scholars used add-ons, including iPhone, iPad, and Kindle, and lauded the technologies for making their work portable. The professors interviewed also cited wireless microphones and video recorders as technologies they used to capture research data:

What I'm interested with technology is that it consolidates my life, not spreads it out more ... it's all together: I've got my e-mail, I have phone, I have

The study participants used computers for all stages of the research, writing, and publication process. Some scholars used add-ons, including iPhone, iPad, and Kindle, and lauded the technologies for making their work portable.

Internet stuff. It's an easy way to have it centralized, versus five devices in my pocket to deal with . . I Is it effective to do something on the Internet? No. But, I can access information on it if I need to pretty quick with [my iPhone].

Associate Professor E.

I've actually given my presentation straight from the iPad, I just have my VGA [video graphics array] cable, so I just connect it directly rather than try to convert it because it doesn't use the same format as PowerPoint. 
Individual researchers see certain technologies as critical for their work. For Assistant Professor A., a desktop scanner is indispensable: "I'm able to store a lot of information electronically and scan it quickly that way ... I can't live without my scanner, that's the most important tool I use." While the scanner plays a critical role in her data storage, Professor A. stated that she also maintains paper copies and uses flash drives to hold files. The use of both electronic and paper files and storage was common among the faculty. The use of more than one electronic storage device was also frequent.

Throughout the technology discussions were other statements that indicate faculty see ways to work with technology in either new or more efficient ways to support their work practices. For example, Full Professor K. said that he could use a laptop instead of writing notes first by hand and then transferring them to the computer, and Assistant Professor C. reported that she could sync her home and office computer instead of bringing files back and forth on a flash drive: "Professor [R.] in the department was telling me that there's a way to have everything synced and be saving things so that you don't have to move anything anywhere."

\section{Technology Challenges}

While these tools have proved to be invaluable, they also come with their own unique challenges. The challenges vary by individual, however. Interviews indicated four main difficulties: finding a match between the technology and faculty members' preferred research practices; overcoming the learning curve and gaining the needed assistance; compatibility, interoperability, and software stability; and financial support. One participant explained:

First, the technology must meet the research needs and practices of the faculty member. I'm struggling with qualitative software, NVivo. The reason I struggle with it is the same reason I struggle with the tactile, is that when I'm working with qualitative data analysis I have to get my hands on it. I have different files that are color-coded by the computer; it's like "Did they get it all?" But, if I have my stacks, I know I have it all.

Associate Professor F.

The time needed to master technologies and software often limited the use of particular tools. Yet faculty saw the benefits if they could overcome the learning curve:

\section{The time needed to master technologies and software often limited the use of particular tools.}

Getting references in format using EndNote, which I'm not really all that savvy with, that would be helpful.

Associate Professor H.

I'm very interested in a citation management software. That is something I've been interested in and just feel like I've never had time to just stop long enough to learn how to use it, or download it, and all of that stuff.

Assistant Professor A.

In addition to the initial learning curve, faculty ran into the challenge of keeping up to date with the variety of tools they were using, for example, updating versions. 
Compatibility, interoperability, and stability of software were other areas of concern. Difficulties encountered due to programs crashing and the loss of data were unacceptable, so such problems led either to nonuse or to choosing a different product:

... not EndNote ... I don't like EndNote. I tried it then I switched to a Mac and this is a much more, in my opinion more stable piece of software ... I had a terrible time with it ... It seemed to crash, I lost data and I just got tired with it.

Associate Professor G.

Faculty described situations where the hardware they used did not work seamlessly with commonly used presentation software. To overcome this type of challenge, they have to take the time to determine what combination of tools works best for them:

When you convert from Keynote you lose a lot of your information, rather than try to convert it to a PowerPoint, and then store the PowerPoint on a key, and then take the key to the computer, I just connect it directly to the projector and run my presentation from the iPad itself.

Assistant Professor A.

Financial challenges were discussed in terms of specialized software. Faculty could not always conduct their research as efficiently as they would like because they are unable to either purchase software themselves or to share their tools with student research assistants:

I think access to maybe good graphic software, that's not so much a problem for me because I actually buy my own graphic software but I know for a lot of new faculty members they are trying to make their graphs in Excel and it's not really good graphic software.

Full Professor I.

I got trained in [NVivo] and then started to use it and then realized that I really didn't have the funds or the ability to train students to use it, that I was the only one who knew it, and it wasn't going to go anywhere that way, so I actually haven't actually used it that much.

Full Professor L.

\section{The Publication Process}

The interviewers asked faculty to describe where they last published their research and why they chose that venue. Most respondents had certain publishers in mind with whom they aimed to publish. Standards and expectations in traditional publishing were well understood, and the relationship of tenure and promotion to publishing seemed foremost in the professors' minds. They often published in journals connected to their disciplines via conferences, societies, or other networking outlets. Most followed a path of presenting a poster session at a conference they regularly attend, then later turning the study results into a journal article. Others selected journals based on credibility and review periods: 
Generally the protocol is to take your hope to be publication to your colleagues at a conference and get whatever feedback you could. Maybe even make some corrections at it and revise based on what you hear at the conference, clean it up, and then you find someplace to submit.

Full Professor K.

We wanted to get it to a journal that had pretty high standard[s] . . . we wanted to get it in the best journal we could. And, we also wanted to try and get it out relatively quickly. This journal is somewhat new and it's looking for manuscripts to expand its readership and I was actually in on the beginning of the journal itself several years ago and haven't been involved in it since and haven't liked the drift and so I wanted to make a point, so those are the reasons we chose that one.

Full Professor J.

Most faculty lacked familiarity with the open-access model of publishing. They were unclear on whether open-access publishing was scholarly or refereed. Those in-

Most faculty lacked familiarity with the open-access model of publishing. terviewed expressed concern that open access lacked the necessary characteristics required for individual performance reviews in their departments:

The issue for me will be, our unit standards wants peer-reviewed and in a journal that is specific to the area that you are responsible for in the department... if it's not appreciated or recognized by the unit or the university then I don't have the time to write, to just write and put it out there.

Associate Professor F.

If I'm paying a journal to publish my stuff, it brings about a lot of other questions about the integrity of that journal. The prestige of that journal.

Associate Professor G.

Yet, some professors expressed interest and saw value in the open sharing of materials:

I don't have a robust enough Web page; it's just a generic thing set up a long time ago. Eventually that would be a great place to do it . . broaden out the sharing in different ways; I don't know how it would work ... here are my papers from my conference and I could put them there so people could then look at the presentations.

Associate Professor E.

\section{Publishing Challenges}

While department standards differ, faculty members faced similar challenges in their publishing efforts. The study participants admitted that finding the right venue in which to publish could be challenging. Keeping up to date and determining the right publisher for monographs in particular was identified as a challenge: 
I was wondering if there were any resources on campus to help with that process ... I've contacted a couple of publishers and haven't gotten a good response ... Where I am kind of stuck now is I need some help trying to figure out where else I could send it or if [the university does] any self-publishing.

Assistant Professor B.

In some cases, faculty find that even though they are aware of possible publishers and understand the submission process, finding a journal that provides the right fit is a challenge. This difficulty is particularly evident with interdisciplinary research, which could result in an article written for multiple audiences. Researchers have little problem if their article is accepted by the first journal they submit to; however, if they need to switch gears later in the process and submit their work to a different journal, they will most likely have to make significant edits to tailor their submission for the new audience, including changes in citation styles:

\section{...faculty find that even though they are aware of possible publishers and understand the submission process, finding a journal that provides the right fit is a challenge.}

[There are a] limited number of journals in my field, there are basically four. I approach this group. I found that, to be perfectly honest, that this is so specialized that I'm going to have to write my own book.

Assistant Professor D.

A related concern with finding the right fit for publishing revolves around the tenure process. Most department standards give a higher priority to peer-reviewed journals or well-known journals within specific subject areas. The focus on peer review and established journals sets a precedent that makes faculty unsure if publishing in open-access publications is a smart option. Even though participants saw the value in making their research publicly available, they saw it as more of a complication to their research decisions than a benefit:

There's a process of what's acceptable scholarship, and there is always barriers on that, that's true for everybody. Your perception of what's valuable or not, and then you have to go through the steps of making it look a particular way to make someone happy.

Associate Professor E.

Some faculty admitted that copyright issues challenged them. In one case, the concern was related to dealing with publishers who viewed a technical report the researcher had published on the same subject as a prepublication of a submitted article. The individual was faced with the option of removing access to the report to enable publication in the journal. In another case, a scholar's draft of a manuscript would need significant editing due to potential copyright concerns: "One of the dilemmas I'm having, too, is that all the pictures are Clipart... All of the pictures for a publication would have to be redone, drawn," explained Assistant Professor B. 


\section{Organization and Storage Practices}

The investigators inquired about what happens to the material generated from research that is not published. Responses indicated that the researchers deal with organizing materials in many different ways. Some impose a structure upon their work, keeping track of notes and drafts in meticulous ways through bibliographic management software and file tree structures, and in a variety of paper and online formats. Others seem to have fallen into a system that works well for them. Still others seemingly have no system at all. While approaches varied, there were similar considerations, such as space, organizational schemes, electronic file formats, and data privacy. Overall, the participants saw materials storage as a challenge.

The physical appearance of faculty offices-where the majority of physical material generated from research was held-was similar. The items stored included file cabinets with grant proposals, stacks of journal articles related to particular projects, bookshelves with each shelf a designated class or research project, and locked data files that included items such as completed surveys and administrative paperwork for Institutional Review Board approved and grant-funded projects. Finding enough physical space to store this material was problematic:

I had this grand idea six years ago that I was just [going to] keep on top of everything so well. Well that actually, well I don't have enough file cabinets for that, because that can really get out of control.

Associate Professor G.

Even if individuals have plenty of space to keep documents, they still struggle with finding a system and the time to keep that system maintained:

\section{Even if individuals have plenty of space to keep documents, they still struggle with finding a system and the time to keep that system maintained.}

You can see my stacks there are kind of messy ... I don't have a great filing system. At the end of the year I tend to look at my office and shriek and say "I've got to fix this, I've got to get things more organized," and I haven't done that yet. Piles of paper and so forth.

Associate Professor H.

Faculty discussed online storage relative to file accessibility, preservation, and transferability. In terms of accessibility, most professors keep their work on their office computer, and some use secondary measures such as maintaining copies on a backup drive or a thumb drive. There were conflicting perspectives on the relative accessibility of older files:

If it's old though, it dies because it doesn't work in the Word doc anymore.

Associate Professor E.

I keep all the data files on a backup hard drive and I actually have a long list of publications that I intend to write. 
Research productivity is lost when data and files are lost:

Some of those documents still have utility to me, I know where they are, and I know the kind of thing I might use them for. But, they are not available electronically, I don't have an electronic, well actually I do have an electronic file, they are on 5.5-inch floppy disks, which of course are unreadable now.

Full Professor J.

Many faculty reported that they use a citation management system to organize their research citations; others said they would like to use such a system. Full Professor I. explained, "I teach students how to use the online EndNote, or online RefWorks, they are welcome to use either one. I really encourage that. I tend to buy the full EndNote program, and use that."

In terms of transferability, some faculty use flash drives, others utilize e-mail, Dropbox, or virtual private networks (VPNs) to move or access files from multiple locations. "I'm saving less and less at home because of the capability to come into this computer," says Associate Professor F., adding, "At home I'll come in through the VPN."

\section{Conclusion}

The authors undertook this project to address three primary goals: to understand research and publication practices of faculty; to recommend new and or modified library services based on these findings; and to inform and recommend marketing and development initiatives to support an institutional repository. Specifically, the authors designed this study to document how select professors in the education and behavioral sciences locate, retrieve, and use information resources for research and writing and how they publish and store their publications.

Research and publication practices of faculty were clearly delineated through this ethnographic methodology. The professors who participated in this research project are active researchers and teachers who find sources for their projects through both active searching and professional affiliations and practices. They make frequent use of library resources and services. They triangulate research, teaching, and mentorship of graduate students, often relying on graduate students to compile working bibliographies for current projects. Faculty lean heavily on e-resources due to the ready accessibility of those resources, and as a result many have changed their reading patterns to consult e-journal articles more than books. Further, they have established research patterns using library resources that do not always take

Faculty lean heavily on e-resources due to the ready accessibility of those resources, and as a result many have changed their reading patterns to consult e-journal articles more than books. advantage of the most efficient and effective research strategies, access, or both. Finally, these professors are strong library supporters. They have a keen understanding of the important role library personnel, resources, and services play in their academic careers. 
Faculty move their research forward in strategic ways, often gathering feedback on their initial work via conference presentations, then publishing in journals connected to their professional associations to meet the standards for tenure. Monograph publishing leads them on a different path. Approaches to research and file management were not consistent, though use of or interest in bibliographic management systems was high. All faculty maintained both electronic and paper files.

Faculty interviews provide a treasure trove of information that not only documents participants' work practices but also can translate into improved library services. Based on the study findings, recommendations for new or modified library services can be used to inform both effective continuing education opportunities within the library and marketing initiatives on campus. Specifically, the subject liaison librarian has an in-depth working knowledge of how faculty in the education and behavioral sciences locate, retrieve, use, publish, and store information as a critical part of their research and writing.

Further research might focus on a specific department or include a larger sample of professors from each department; narrow to cover one work practice in depth, such as file storage; or expand to further explore study findings, such as the factors that lead faculty to consult the library. This qualitative research provides an in-depth exploration of the research and writing practices of select faculty within particular fields of study. While not generalizable, the methodology can be used to extend this research to other departments and the findings can serve as points of comparison among disciplines.

Kate Zoellner is associate professor, assessment coordinator, and education, human sciences, and psychology librarian at the Maureen and Mike Mansfield Library (Mansfield Library) at the University of Montana in Missoula (UM). She may be reached at: kate.zoellner@umontana.edu.

Samantha Hines is associate professor and head of the Mansfield Library at Missoula College of UM. She may be reached at: samantha.hines@umontana.edu.

Teressa Keenan is associate professor and head of bibliographic management services at the Mansfield Library at UM. She may be reached at: teressa.keenan@umontana.edu.

Sue Samson is professor, library instruction coordinator, and humanities librarian at the Mansfield Library at UM. She may be reached at: sue.samson@umontana.edu.

\section{Appendix}

\section{Faculty Research and Publication Practices Interview Instrument}

\section{Introduction}

From your Web site, we see that you have done research on [insert general topic]. We are interested in learning more about how you do research and how you publish and store the results of that research. 


\section{General}

Please describe one of your current research projects.

Do you have something handy you are currently reading that is related to your research you can share with us? How did you find out about this item? How did you acquire it?

- [If yes] Could you show us how you go about the process?

- [If no] Are you currently looking for books, articles, etc. for the research? Could you show us how you go about the process?

Did you face any challenges in the process of finding and accessing this item (refer to item they have been discussing])? [If yes]:

- What are the challenges?

- Do you think the challenges are specific to your discipline(s)? Why?

\section{Research Support}

Does the library play a role in your research? [If yes]:

- What role does it play?

- At what stage(s) of your research are you most likely to use the library?

- What resources do you generally use?

What role does technology play in your research? Do you use your computer in your research? (e.g. electronic indexes, digital archives, databases, GIS, word processing, statistical packages, drawing tools, bibliographic management tools, etc.)?

\section{Publication and Storage}

Where's the last place you published or shared your research? Why did you choose to publish there?

Do you ever share the same research in multiple places? [If yes] Why? Where?

What happens to the material generated in your research that does not get published, such as research notes, drafts, preprints, data sets, etc.? 
Are you familiar with open-access publishing? [If yes]:

- How did you learn about it?

- Have you ever published or stored your research in an open-access publication or repository? Why?

\section{Office Tour}

\section{Final Item}

Is there anything else you want to share with us?

\section{If Time Permits}

Is your work collaborative or interdisciplinary? If yes, what special challenges do you face? What are the benefits of interdisciplinary or collaborative methods to your research?

What kind of assistance do you need or seek for your research? Does anyone provide research assistance to you? Who?

When submitting your work for publication/dissemination, what would make the process easier for you?

Let's say I can give you something that will magically make it better for you to do your work. What does this make it possible for you to do?

Describe your ideal research environment.

\section{Notes}

1. Karen Rupp-Serrano and Sarah Robbins, "Information-Seeking Habits of Education Faculty," College \& Research Libraries 74, 2 (2013): 134, accessed March 25, 2014, http:/ / crl. acrl.org/ content/74/2/131.full.pdf.

2. Ibid., $135,138-39$.

3. Inna Shpilko, "Assessing Information-Seeking Patterns and Needs of Nutrition, Food Science, and Dietetics Faculty," Library \& Information Science Research 33, 2 (2011): 151-57, doi: 10.1016/j.lisr.2010.07.018.

4. Sarah Robbins, Debra Engel, and Christina Kulp, “How Unique Are Our Users? Comparing Responses Regarding the Information-Seeking Habits of Engineering Faculty," College \& Research Libraries 72, 6 (2011): 522-23, http:/ / crl.acrl.org/ content/72/6/515.full. pdf.

5. Ibid., 524 .

6. Sarah Robbins and Karen Rupp-Serrano, "How Unique Are Our Users? Part 2: Comparing Responses Regarding the Information-Seeking Habits of Education Faculty," College \& Research Libraries 74, 5 (2013): 450-63, http:/ / crl.acrl.org/ content/ 74/5/450.full.pdf.

7. Ibid., 450 . 
8. Roger C. Schonfeld, Ross Housewright, and Kate Wulfson, Ithaka $S+R$ US Faculty Survey 2012 (New York: Ithaka S + R, April 8, 2012), 6, accessed July 23, 2014, http: / / www. sr.ithaka.org/sites/default/files/reports/Ithaka_SR_US_Faculty_Survey_2012_FINAL.pdf.

9. Ibid., 6-7.

10. Michael Khoo, Lily Rozlakis, and Catherine Hall, "A Survey of the Use of Ethnographic Methods in the Study of Libraries and Library Users," Library and Information Science Research 34, 2 (2012): 82-91, doi: 10.1016/j.lisr.2011.07.010.

11. Ibid., 83.

12. Ellen L. Freeman and Marilyn R. Pukkila, "Faculty in the Mist: Ethnographic Study of Faculty Research Practices," in Participatory Design in Academic Libraries: Methods, Findings, and Implementations, ed. Nancy Fried Foster (Washington, DC: Council on Library and Information Resources [CLIR], 2012), 4-9, accessed July 23, 2014, http:/ / www.clir.org/ pubs/reports/pub155/pub155.pdf

13. Valeda Dent Goodman, "Applying Ethnographic Research Methods in Library and Information Settings," Libri 61, 1 (2011): 5, doi: 10.1515/libr.2011.001.

14. University of Minnesota Libraries, A Multi-Dimensional Framework for Academic Support: A Final Report Submitted to the Andrew W. Mellon Foundation (June 2006), 61, accessed July 23, 2014, http:/ / www1.lib.umn.edu/about/mellon/UMN_Multi-dimensional_Framework_ Final_Report_Appendices.pdf; Nancy Fried Foster, "Faculty Interview Protocol" (unpublished instrument, CLIR Faculty Research Behavior Workshop, Cambridge, MA, 2010).

15. Steven Bell, "Transforming the Library Starts with Mapping the Journey" (keynote address, American Library Association Virtual Conference, July 25, 2013). 